\title{
Efeito da fonte de óleo e dos níveis de suplementação de vitamina E na ração sobre o congelamento de sêmen de suínos ${ }^{1}$
}

\section{Elenice Andrade Moraes ${ }^{2}$, Ciro Alexandre Alves Torres ${ }^{3}$, José Domingos Guimarães ${ }^{4}$, Giovanni Ribeiro de Carvalho ${ }^{3}$, Luis David Solis Murgas ${ }^{5}$, Eduardo Paulino da Costa ${ }^{4}$}

\author{
1 Pesquisa financiada pela FAPEMIG. \\ 2 Colegiado de Zootecnia, Universidade Federal do Vale do São Francisco, Petrolina - PE. \\ ${ }^{3}$ Departamento de Zootecnia, Universidade Federal de Viçosa, Viçosa - MG. \\ ${ }^{4}$ Departamento de Veterinária, Universidade Federal de Viçosa, Viçosa - MG. \\ 5 Departamento de Veterinária, Universidade Federal de Lavras, Lavras - MG.
}

RESUMO - Objetivou-se avaliar os efeitos da adição de fontes de óleo e dos níveis de suplementação de vitamina E na ração sobre a criopreservação de sêmen suíno. Foram utilizados 24 suínos machos reprodutores Dalboar 85, com idades de 12 a 18 meses, distribuídos em delineamento inteiramente casualizado, em arranjo fatorial $2 \times 3$, com duas fontes de óleo (soja e salmão) e três níveis de vitamina E $(150,300$ e $450 \mathrm{mg} / \mathrm{kg})$. O sêmen foi coletado semanalmente (1 coleta/macho), diluído com meio centrifugador $(1: 1)$ e mantido a $25^{\circ} \mathrm{C}$ por 2 horas. Após centrifugação ( $800 \mathrm{~g}, 10$ minutos), o pélete foi suspenso com meio de congelamento para concentração final de $1 \times 10^{9}$ espermatozoides $/ \mathrm{mL}$. O sêmen foi envasado em palhetas de $0,5 \mathrm{~mL}$ e colocado dentro de tubo de ensaio $\left(17^{\circ} \mathrm{C}, 35\right.$ minutos). Após esse período, as palhetas foram retiradas do tubo e mantidas por 25 minutos, quando foram submetidas a vapor de nitrogênio por 20 minutos e mergulhadas em nitrogênio líquido. Após o descongelamento, o sêmen dos animais alimentados com a ração acrescida de óleo de soja reduziu a motilidade, o vigor, a porcentagem de espermatozoides vivos e o teste hiposmotico. A motilidade média do sêmen após a diluição e durante as etapas do congelamento foi de 85 e $84 \%$ para os animais que receberam óleo de salmão e soja, respectivamente. Entretanto, após o descongelamento, a motilidade dos espermatozoides dos animais alimentados com a ração contendo óleo de salmão e soja reduziu para 30 e $24 \%$, respectivamente. O sêmen dos animais tratados com óleo de soja apresentou menor porcentagem de espermatozoides vivos e morfologia normal em comparação aos tratados com óleo de salmão. A suplementação com óleo de salmão na dieta de suínos promove redução das características negativas observadas no sêmen suíno descongelado.

Palavras-chave: ácidos graxos, congelamento, espermatozoides, óleo de salmão

\section{Effect of oil sources supplementation levels of E vitamin in the diet on the boar semen cryopreservation}

\begin{abstract}
The objective of this work was to evaluate the effects of addition of oil and of levels of supplementation of E vitamin on the boar sperm cryopreservation. It was used 24 Dalboar 85 boars, at 12 to 18 months, distributed in a complete random design, in a $2 \times 3$ factorial arrangement, with two source of oil (soybean and salmon) and three levels of E vitamin $(150,300$ and $450 \mathrm{mg} / \mathrm{kg})$. Semen was collected weekly (1 collection/male), diluted in centrifuge media (1:1) and kept at $25^{\circ} \mathrm{C}$ for 2 hours. After centrifugation ( $800 \mathrm{~g}, 10$ minutes), the pellet was suspended in freezing medium for the final concentration of $1 \times 10^{9}$ sperm $/ \mathrm{mL}$. The semen was packaged into $0.5 \mathrm{~mL}$ straws and placed inside a test tube $\left(17^{\circ} \mathrm{C}, 35\right.$ minutes $)$. After this period, the straws were removed from the tube and kept for 25 minutes more, submitted to nitrogen vapor for 20 minutes and then dip into liquid nitrogen. After thawing, the semen of animals fed the ration added with soybean oil reduced motility, vigor, percentage of live sperm and HOST. The average motility of the semen after dilution and during cryopreservation process was 85 and $84 \%$ for the animals fed salmon and soybean oil, respectively. However, after thawing, the motility of the sperms of animals fed ration with salmon and soybean oil was reduced to 30 and $24 \%$, respectively. Semen of animals treated with soybean oil presented lower percentage of live sperm and normal morphology when compared to the ones treated with salmon oil. Supplementation of salmon oil in diet for swines reduces the negative traits observed in thawed semen of boars.
\end{abstract}

Key Words: fatty acids, freezen, salmon oil, sperm 


\section{Introdução}

Os processos de congelamento do sêmen suíno têm poucas aplicações práticas quando comparados aos de outras espécies de mamíferos domésticos, principalmente devido à grande variabilidade nos resultados de fertilidade após inseminação com doses de sêmen descongeladas (Paquignon et al., 1977; Toniolli et al., 2001). Durante as etapas do congelamento do sêmen, deve-se considerar a complexidade bioquímica da membrana plasmática do espermatozoide, a interação de seus componentes e a influência do resfriamento, congelamento e descongelamento nessas interações.

Diferenças na composição de lipídios da membrana espermática têm sido reportadas como um fator chave na diferenciação da congelabilidade dos espermatozoides (Parks \& Lynch, 1992). Em muitas espécies de mamíferos, mais de $60 \%$ dos ácidos graxos da membrana espermática são ácidos graxos poliinsaturados (PUFA) de cadeia longa da serie ômega 3 ( $\omega 3$ ) (Poulos et al., 1973; Nissen \& Kreysel, 1983). Esta específica composição de lipídios confere uma maior fluidez à membrana plasmática devido à presença de algumas ligações duplas (Erickson, 1998). Os lipídios que compõem a membrana plasmática dos espermatozoides de suínos são particularmente os insaturados, ácido docosahexanoico (DHA, 30\%) e docosapentanoico (DPA, $25 \%$ ) (Penny et al., 2000). A alteração da composição de lipídios da membrana espermática afeta o congelamento dos espermatozoides (Steponkus et al., 1983) e a possibilidade de aumentar a congelabilidade de espermatozoides suínos por meio da alteração da constituição da membrana espermática, como exemplo o aumento do teor de DHA na membrana plasmática por meio de sua adição à dieta, é considerada (Penny et al., 2000). O aumento deliberado do grau de insaturações e, portanto da fluidez da membrana, poderia aumentar a resistência dos espermatozoides suínos aos danos causados pelo processo de resfriamento/ descongelamento (Paulenz et al., 1999).

Óleo de salmão apresenta na sua composição $13 \%$ de DHA, enquanto o óleo de soja não possui nenhuma porcentagem de DHA, DPA e EPA (Reese, 2003). Assim, o óleo de salmão pode ser uma opção para aumentar o conteúdo de ácidos graxos (DHA e DPA) na membrana de espermatozoides de suínos e o óleo de salmão um grupo controle para avaliar esta adição nos resultados de congelamento do sêmen de suínos.

Entretanto, apesar dos efeitos benéficos dos ácidos graxos $\omega 3$, altas concentrações de ácidos graxos poliinsaturados (PUFA) torna os espermatozoides altamente susceptíveis à peroxidação com conseqüente risco de danos à estrutura celular (Niki et al., 1993). Assim, objetivou-se avaliar o efeito de diferentes fontes de óleo e níveis de suplementação de vitamina E sobre o processo de congelamento do sêmen suíno de reprodutores.

\section{Material e Métodos}

O experimento foi conduzido de setembro de 2005 a janeiro de 2006, a $27^{\circ} 00^{\prime} 30^{\prime \prime}$ de latitude sul e $51^{\circ} 09^{\prime} 06^{\prime \prime}$ de longitude oeste, altitude média de $750 \mathrm{~m}$, clima Cfa, segundo classificação de Koppen-Geiger (verão quente), com temperatura média anual de $17^{\circ} \mathrm{C}$ e precipitação pluviométrica média anual de $1.800 \mathrm{~mm}$.

Foram utilizados 24 suínos machos reprodutores Dalboar 85, com 12 a 18 meses de idade, alojados em baias individuais com água ad libitum e suplementação concentrada diária, segundo exigências estabelecidas pelo NRC (1998). Os animais foram distribuídos num delineamento inteiramente casualizado, em arranjo fatorial $2 \times 3$, com duas fontes de óleo (soja e salmão) e três níveis de vitamina $\mathrm{E}(150,300$ e $450 \mathrm{mg} / \mathrm{kg}$ de ração). Foram adicionados 3,5\% de óleo, independente da fonte utilizada.

As amostras de sêmen foram coletadas, semanalmente ( 1 coleta/macho/semana), pelo método da mão enluvada (King \& Macpherson, 1973), em sala apropriada com um manequim. O sêmen foi coletado em copo plástico de $700 \mathrm{~mL}$, contido em um copo térmico, com água previamente aquecida a $37^{\circ} \mathrm{C}$. Imediatamente após a coleta, o ejaculado foi levado ao laboratório de processamento de sêmen, onde foi colocado em banho-maria à temperatura de $37^{\circ} \mathrm{C}$ para avaliações da qualidade.

Imediatamente após a coleta do sêmen, o ejaculado foi analisado quanto à motilidade e vigor espermático, conforme normas do CBRA (1998).

As avaliações da motilidade e do vigor espermático do sêmen durante o período de pré-congelamento foram realizadas em seis etapas: 1 = sêmen in natura; 2 = sêmen diluído com meio centrifugador; 3 = sêmen centrifugado; 4 = sêmen diluído com meio de congelamento; 5 = sêmen diluído com meio de congelamento após o resfriamento; 6 = sêmen após congelamento no vapor de nitrogênio líquido e imediatamente avaliado quanto à motilidade espermática.

A avaliação da motilidade total (\%) e do vigor espermático foi examinada em microscopia de contraste de fase em aumento de 200x, utilizando uma alíquota de $10 \mu \mathrm{L}$ de sêmen diluído 1:1 com diluente BTS, depositada entre lâmina e lamínula, ambas mantidas a $37^{\circ} \mathrm{C}$. O vigor foi classificado de acordo com Ferreira Neto et al. (1977), variando de zero (0) a cinco (5), sendo o escore 0 equivalente 
Tabela 1 - Composição por $100 \mathrm{~mL}$ do meio de centrifugação glicose-EDTA

\begin{tabular}{lc}
\hline Reagente & Quantidade \\
\hline $\mathrm{D}(+)$ glicose monohidratada & $6,000 \mathrm{~g}$ \\
Citrato de sódio & $0,375 \mathrm{~g}$ \\
EDTA & $0,370 \mathrm{~g}$ \\
Bicarbonato de sódio & $0,125 \mathrm{~g}$ \\
Penicilina G (sódica ou potássica) & $100,000 \mathrm{UI}$ \\
Sulfato de estreptomicina & $0,100 \mathrm{~g}$ \\
\hline
\end{tabular}

EDTA = etileno diaminotetra-acetodissódico. Fonte: Martin et al. (1979).

Tabela 2 - Composição do meio de congelamento

\begin{tabular}{lc}
\hline Reagentes & Quantidade $(\mathrm{mL})$ \\
\hline Solução de lactose a $11 \%$ & 50,0 \\
Diluente de centrifugação & 25,0 \\
Glicerol & 5,0 \\
Gema de ovo & 20,0 \\
Orvus-es-paste* & 0,8 \\
\hline * Volume adicionado sobre o volume dos demais reagentes após adição da gema \\
de ovo. Fonte: Martin et al. (1979).
\end{tabular}

à total imobilidade espermática e o escore 5, à movimentação intensa, vigorosa, progressiva e com formação de ondas.

O sêmen foi processado e congelado pelo método descrito por Fürst et al. (2005), modificado quanto ao período de incubação a temperatura ambiente. O ejaculado foi diluído com meio centrifugador (Tabela 1) na proporção de 1:1 e, mantidos à temperatura ambiente de 23 a $25^{\circ} \mathrm{C}$. por 120 minutos, sendo posteriormente, centrifugados a $800 \mathrm{G}$ por 10 minutos. O meio de congelamento (Tabela 2) foi adicionado à temperatura de $17^{\circ} \mathrm{C}$. Após a centrifugação e retirada do plasma seminal, os péletes foram ressuspendidos com meio de congelamento para uma concentração final de 1 bilhão de espermatozoides por $\mathrm{mL}$. Para determinar esta concentração, foi utilizado a câmara de Neubauer, diluindo-se $20 \mu \mathrm{L}$ de sêmen em $2 \mathrm{~mL}$ (diluição de 1:100) de solução formol salina tamponada a 1\%. Após a homogeneização da mistura, uma alíquota foi colocada na câmara, onde a contagem foi feita sob microscopia de contraste de fase (aumento de 400x).

Alíquotas foram retiradas para análise física dos espermatozoides. O sêmen foi envasado em palhetas de $0,5 \mathrm{~mL}$ na concentração final de $500 \times 10^{6}$ espermatozoides/palheta. As palhetas contendo o sêmen foram colocadas dentro de tubo de ensaio de $20 \mathrm{~mL}$ mantidos anteriormente a temperatura de $17^{\circ} \mathrm{C}$. Em seguida, o tubo de ensaio revestido por um refil (saco plástico) foi colocado dentro de um recipiente de plástico de $240 \mathrm{~mL}$, contendo $120 \mathrm{~mL}$ de álcool absoluto preenchendo a metade do tubo de ensaio, que também estava mantido à temperatura de $17^{\circ} \mathrm{C}$. O recipiente foi, então, colocado na posição horizontal em geladeira, com temperatura interna de 4 a $5^{\circ} \mathrm{C}$, com taxa média de $-0,5^{\circ} \mathrm{C}$ de descrécimo da temperatura, por um período de resfriamento de 35 minutos. Após este período, o tubo de ensaio contendo as palhetas foi retirado do recipiente $\mathrm{e}$ mantido na temperatura da geladeira por mais 25 minutos, que foi o tempo de equilíbrio.

O congelamento foi realizado em vapor de nitrogênio, colocando as palhetas sobre um suporte de aço inox a $5 \mathrm{~cm}$ da superfície do nitrogênio líquido, acondicionado em uma caixa de isopor, durante 20 minutos. Após esse período as palhetas foram submersas no nitrogênio, para congelamento final dos espermatozoides. Em seguida, foram colocadas em raques, devidamente identificadas e armazenadas em botijão de nitrogênio, para análises posteriores. As amostras de sêmen de cada tratamento foram descongeladas em banho-maria a $37^{\circ} \mathrm{C}$ por 20 segundos (Ohata et al., 2005), e a motilidade e o vigor espermático foram avaliados. A integridade da membrana plasmática foi avaliada no sêmen diluído descongelado, conforme a técnica da preparação úmida (CBRA, 1998). Alíquotas de $10 \mu \mathrm{L}$ do sêmen diluído foram adicionadas em $0,9 \mathrm{~mL}$ da solução à base de citrato de sódio e frutose com osmolaridade de $150 \mathrm{mOsmol} / \mathrm{L}$ (Vazquez et al., 1997), e incubado por 30 minutos, em banhomaria à $37^{\circ} \mathrm{C}$. Após esse período, alíquotas de $15 \mu \mathrm{L}$ da mistura foram colocadas entre lâmina e lamínula, para a contagem de 100 células de cada solução em microscopia de contraste de fase com aumento de 400x. As células foram classificadas quanto à presença ou não da cauda enrolada, segundo descrito por Kumi-Diaka (1993).

Para a avaliação da morfologia espermática utilizou-se a técnica de preparação úmida. Alíquotas de $40 \mu \mathrm{L}$ de sêmen foram adicionadas em $1 \mathrm{~mL}$ de formol-salino tamponado e estocado a temperatura ambiente até análises. Foram contadas 100 células, com auxílio de microscópio óptico com contraste de fase, em aumento de 1000x para a determinação do percentual de anormalidades espermáticas classificadas segundo CBRA (1998), classificando as anormalidades em defeitos maiores e menores.

As análises dos parâmetros avaliados foram realizadas com utilização do programa SAEG (UFV, 1997). As variáveis foram submetidas aos testes de normalidade e homocedacidade. Posteriormente, foram submetidas à análise de variância dos dados e utilizadas o teste de Student Newman-Keuls (SNK) para comparação de médias entre as fontes de óleo, com nível de significância de $5 \%$ e análise de regressão para os níveis de antioxidantes usados. Quando houve interação foi determinado o efeito do nível de antioxidante dentro de cada fonte. As variáveis que não atenderam às premissas para a análise de variância, mesmo após as transformações, foram submetidas ao teste não paramétrico de Wilcoxon-SAEG(UFV, 1997). 


\section{Resultados e Discussão}

Não foi observada interação entre a fonte de óleo e os níveis de vitamina $\mathrm{E}(\mathrm{P}>0,05)$. A motilidade espermática total média foi acompanhada para verificar se houve perda neste parâmetro durante as etapas de processamento do sêmen, principalmente durante o resfriamento e congelamento no vapor de nitrogênio liquido. A motilidade foi analisada após a execução de cada etapa (Figura 1).

No entanto, os resultados de motilidade espermática total no pré-congelamento ( 85 e $84 \%$, respectivamente, para os óleos de salmão e soja) foram superiores aos reportados por Bianchi et al. (2005b), que, utilizando dois diferentes protocolos, observaram motilidade espermática total de 68\% (Westendorf et al., 1975) e 52\% (Paquignon et al., 1974) no pré-congelamento. Vale ressaltar que a motilidade espermática total do sêmen dos animais tratados com óleo de salmão na ração foi maior que a motilidade espermática total pós-descongelamento (22\%) observada por Bianchi et al. (2005b), utilizando o protocolo preconizado por Paquignon et al. (1974), mesmo após 10 e 30 minutos de descongelamento. Os níveis de vitamina E não influenciaram o resultado de motilidade $(\mathrm{P}>0,05)$.

Após o descongelamento, a média da motilidade espermática total dos animais tratados com óleo de salmão ou soja foi de 30 e $24 \%$, respectivamente. Amostras de sêmen dos animais tratados com óleo de salmão na ração apresentaram valores de motilidade espermática total e vigor espermático $(\mathrm{P}<0,05$; Tabela 3$)$, porcentagem de espermatozoides vivos $(\mathrm{P}<0,05$; Tabela 4$)$ e porcentagem de espermatozoides responsivos ao teste hiposmótico $(\mathrm{P}<0,05$; Tabela 6) superiores aos dos tratados com óleo de soja.
Os valores médios das características observadas aproximam-se dos padrões de normalidade considerados para a espécie (CBRA, 1998). Vale ressaltar que, na seleção dos varrões para este estudo, não se utilizaram as características seminais como fator determinante, visto não

Tabela 3 - Motilidade espermática total e vigor espermático do sêmen descongelado de suínos submetidos a suplementação com óleo de soja ou de salmão e vitamina $\mathrm{E}$

\begin{tabular}{lccccc}
\hline Fonte de & \multicolumn{4}{c}{ Nível de vitamina E (mg/kg) } & \\
\cline { 2 - 4 } & 150 & 300 & 450 & Média & CV (\%) \\
\hline \multicolumn{5}{c}{ Motilidade espermática total $(\%)$} \\
Soja & 23,8 & 25,2 & 24,3 & $24,4 \mathrm{~b}$ & \\
Salmão & 27,7 & 31,1 & 31,2 & $30,0 \mathrm{a}$ & \\
Média & $25,8 \mathrm{~B}$ & $28,1 \mathrm{~A}$ & $27,7 \mathrm{~A}$ & & 14,5 \\
\multicolumn{5}{c}{ Vigor } & espermático \\
Soja & 1,97 & 1,85 & 1,85 & $1,89 \mathrm{~b}$ & \\
Salmão & 1,97 & 2,32 & 2,37 & $2,22 \mathrm{a}$ & \\
Média & 1,97 & 2,08 & 2,11 & & 52,3 \\
\hline
\end{tabular}

a,b/A,B - Médias seguidas de letras diferentes, na mesma linha/coluna, diferem $(\mathrm{P}<0,05)$ pelo teste $\mathrm{SNK}$. CV $=$ coeficiente de variação.

Tabela 4 - Porcentagem de espermatozoides vivos no sêmen descongelado de suínos submetidos a suplementação com óleo de soja ou de salmão e vitamina $\mathrm{E}$

\begin{tabular}{lccccc}
\hline Fonte de & \multicolumn{4}{c}{ Nível de vitamina $\mathrm{E}(\mathrm{mg} / \mathrm{kg})$} \\
\cline { 2 - 4 } & 150 & 300 & 450 & Média & CV (\%) \\
\hline Soja & 35,9 & 36,0 & 36,5 & $36,1 \mathrm{~b}$ & \\
Salmão & 39,6 & 42,9 & 42,3 & $41,6 \mathrm{a}$ & \\
Média & $37,7 \mathrm{~B}$ & $39,5 \mathrm{~A}$ & $39,4 \mathrm{~A}$ & & 12,7 \\
\hline
\end{tabular}

a,b/A,B - Médias seguidas de letras diferentes, na mesma linha/coluna, diferiram $(\mathrm{P}<0,05)$ pelo teste $\mathrm{SNK}$. CV $=$ coeficiente de variação.

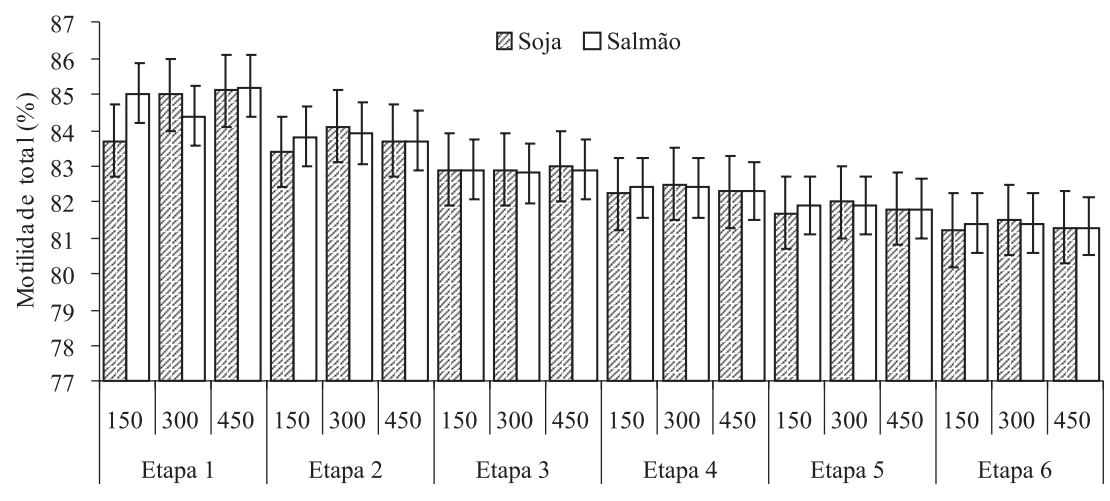

Etapas: 1) sêmen in natura; 2) sêmen diluído com meio de centrifugação; 3) sêmen centrifugado; 4) sêmen diluído com meio de congelamento; 5) sêmen diluído com meio de congelamento após o resfriamento; 6) sêmen após o congelamento no vapor de nitrogênio líquido. * $\mathrm{P}>0,05$.

Figura 1 - Motilidade espermática total, durante as etapas do protocolo de resfriamento e congelamento, do sêmen de suínos submetidos a suplementação com óleo de soja ou de salmão e três níveis de vitamina E (150, 300 e $450 \mathrm{mg} / \mathrm{kg})$. 
ser o objetivo do mesmo verificar a capacidade de congelabilidade dos respectivos varrões, mas sim avaliar os danos sofridos pelos espermatozoides após o descongelamento do sêmen.

A motilidade espermática total no pós-descongelamento obtida neste estudo foi mais baixa em relação a outros estudos com sêmen suíno congelado: 38,8\% (Paulenz et al., 1999), 40,9\% (Murgas et al., 2001), 44,6\% (Cerolini et al., 2001), 36\% (Bianchi et al., 2005b, utilizando o protocolo de Westendorf et al. (1975) e 51,4\% (Ohata et al., 2005). Isto pode ser explicado pelo tipo de protocolo de resfriamento e congelamento utilizado, pois os autores adotaram protocolos diferenciados para congelamento do sêmen que foi associado ao período de incubação do sêmen antes do resfriamento. Entretanto, os valores de motilidade espermática total (30\%) dos animais tratados com óleo de salmão foram próximos as obtidas por Bianchi et al. (2005a) que avaliaram dois diferentes diluentes a base de gema de ovo e lipoproteína de baixa densidade (LDL), obtendo valores 10 minutos após o descongelamento de 34 e $33 \%$ de motilidade espermática total. E maiores que os reportados por Maldjian et al. (2005), que suplementaram a ração de suínos com óleo de peixe e obtiveram $24,9 \%$ de motilidade espermática total após o congelamento.

Observou-se efeito linear $(\mathrm{P}<0,05)$ da vitamina $\mathrm{E}$ sobre a motilidade espermática total, porcentagem de espermatozoides vivos e teste hiposmótico para ambas as fontes de óleo. Os maiores níveis de suplementação de vitamina E promoveram melhoria destas variáveis, demonstrando que a função antioxidante da vitamina $\mathrm{E}$ colaborou para os bons resultados obtido no sêmen dos animais suplementados com óleo de salmão.

Em comparação ao sêmen dos animais sem suplementação, o sêmen dos animais sob suplementação com óleo de salmão apresentou maior porcentagem de espermatozoides vivos e menor quantidade de espermatozóides vivos com defeitos maiores (Tabela 4 e 5; $\mathrm{P}<0,05)$ e isso comprova que o óleo de salmão, rico em PUFA, melhora a qualidade do sêmen descongelado.

No entanto, a porcentagem de espermatozoides vivos no sêmen dos animais tratados com óleo de salmão foi similar aos de Cerolini et al. (2001) e Murgas et al. (2001) que obtiveram $42,2 \%$ e $43,0 \%$ de espermatozoides vivos, respectivamente e, menor se comparado aos de Maldjian et al. (2005), que reportaram $56,8 \%$ espermatozoides vivos após descongelamento do sêmen dos animais suplementados com óleo de peixe que foram congelados segundo o protocolo preconizado por Westendorf et al. (1975) e modificado por Almlid(1987).
A porcentagem de espermatozoides vivos foi maior que o número de espermatozoides com motilidade espermática total, e isso sugere que a coloração eosinanigrosina requer apenas a integridade estrutural da membrana espermática para indicar se a célula está integra ou não. Portanto, os espermatozóides, apesar de apresentarem a membrana plasmática da cabeça intacta, possivelmente já podem estar passando por uma fase de esgotamento do ATP, na peça intermediária, não caracterizando assim, alteração na integridade estrutural da membrana plasmática, o que foi também observado por Mello \& Henry (1999).

Os defeitos menores não diferiram $(\mathrm{P}>0,05)$ entre os tratamentos (Tabela 5) e mantiveram-se dentro de padrões desejáveis para efeito de seleção de varrões, pois a porcentagem de defeitos totais registrados em espermatozoides de ambos os tratamentos, são considerados padrão após o descongelamento, segundo as normas preconizadas pelo CBRA(1998).

O teste hiposmótico (HOST) avalia a integridade funcional da membrana plasmática, com base em suas propriedades osmóticas, e, segundo Perez-Llano et al. (2001), os valores desse teste acrescentam informações que podem melhorar significativamente a predição da fertilidade. Neste estudo, o número de espermatozoides reativos ao

Tabela 5 - Morfologia espermática do sêmen descongelado de suínos submetidos a suplementação com óleo de soja ou de salmão e vitamina $\mathrm{E}$

\begin{tabular}{lccccc}
\hline Fonte de & \multicolumn{4}{c}{ Nível de vitamina $\mathrm{E}(\mathrm{mg} / \mathrm{kg})$} & \\
\cline { 2 - 4 } & 150 & 300 & 450 & Média & CV (\%) \\
\hline Soja & 26,4 & 26,4 & 26,3 & $26,3 \mathrm{a}$ & \\
Salmão & 25,9 & 25,9 & 25,7 & $25,8 \mathrm{~b}$ & \\
Média & 26,2 & 26,1 & 26,0 & & 7,54 \\
& \multicolumn{5}{c}{ Defeitos maiores (\%) } \\
Soja & 15,7 & 15,9 & 14,9 & $15,5 \mathrm{a}$ & \\
Salmão & 14,9 & 15,1 & 14,5 & $14,8 \mathrm{a}$ & \\
Média & 15,3 & 15,5 & 14,7 & & 34,9 \\
\hline
\end{tabular}

a,b - Médias seguidas de letras diferentes, na mesma coluna, diferiram pelo teste SNK $(\mathrm{P}<0,05)$. CV = coeficiente de variação.

Tabela 6 - Porcentagem de espermatozoides reativos ao teste hiposmótico no sêmen descongelado de suínos sob suplementação com vitamina $\mathrm{E}$

\begin{tabular}{lccccc}
\hline $\begin{array}{l}\text { Fonte de } \\
\text { óleo }\end{array}$ & \multicolumn{3}{c}{ Nível de vitamina E (mg/kg) } & \\
\cline { 2 - 4 } & 150 & 300 & 450 & Média & CV (\%) \\
\hline & \multicolumn{5}{c}{ Teste hiposmótico (\%) } \\
Soja $^{1}$ & 16,8 & 18,2 & 17,3 & $17,4 \mathrm{~b}$ & \\
Salmão $^{1}$ & 20,7 & 24,1 & 24,2 & $23,0 \mathrm{a}$ & \\
Média $^{18,8 \mathrm{~B}}$ & $21,1 \mathrm{~A}$ & $20,7 \mathrm{~A}$ & & 19,6 \\
\hline
\end{tabular}

Médias seguidas de letras diferentes na mesma linha/coluna diferiram $(\mathrm{P}<0,05)$ pelo teste SNK. CV = coeficiente de variação. ${ }^{\mathrm{I}}$ Efeito linear $(\mathrm{P}<0,05)$. 
teste no sêmen dos animais sob suplementação com óleo de salmão na ração foi maior $(\mathrm{P}<0,05)$ que no sêmen daqueles sob suplementação com óleo de soja (Tabela 6).

Os espermatozoides de suínos são mais susceptíveis a danos durante a diminuição da temperatura que os de outras espécies (Watson et al., 1992), provavelmente devido à composição da membrana plasmática. Mudanças na composição e estrutura da membrana plasmática de espermatozoides de suínos devido ao choque térmico a $17^{\circ} \mathrm{C}$ (De Leeuw et al., 1990) e no congelamento (Buhr et al., 1994) tem sido reportadas. Perez-Llano et al. (2001) observaram que o teste hiposmótico de sêmen suíno foi mais sensível aos danos causados pelo choque térmico (37 a $15^{\circ} \mathrm{C}$ ) que a avaliação da motilidade espermática total e do acrossoma.

Foi feita uma correlação entre a motilidade espermática total e a funcionalidade da membrana, onde se verificou os seguintes valores $r=0,99$ e $r=1,00$ para fonte de óleo de soja e salmão, respectivamente. Essa correlação é alta, pois a motilidade espermática total é dependente do transporte de soluções através da membrana íntegra e das atividades bioquímicas do metabolismo espermático (Jeyendran et al., 1984).

No entanto, o valor de $23 \%$ de espermatozoides reativos ao teste hiposmótico, apesar de baixo, é significativo, visto que, vem representar a porcentagem de espermatozoides reativos de um total de $30 \%$ de espermatozoides móveis (Tabela 3), ou seja, destes 30\% de espermatozoides moveis, $23 \%$ apresentam a membrana plasmática funcional após a etapa de congelamento e descongelamento. Segundo Maxwell \& Johnson (1997), as alterações que podem ocorrer nos espermatozoides após o congelamento estão associadas com a etapa de resfriamento, e essas alterações podem ser minimizadas se o sêmen tiver um período de incubação posterior ao resfriamento. Quando amostras de sêmen prédiluídas são mantidas acima de $15^{\circ} \mathrm{C}$, por 1 a 5 horas, o espermatozoide adquire uma resistência gradual ao choque térmico (Pursel et al., 1972, 1973). Portanto, apesar de, em todos os parâmetros avaliados, o sêmen dos animais que receberam óleo de salmão na ração apresentarem resultados melhores que os tratados com óleo de soja $(\mathrm{P}<0,05)$, nenhum outro ganho foi observado em termos de melhoria da qualidade seminal mesmo após um período de incubação a $15^{\circ} \mathrm{C}$ por 2 horas antes de o sêmen ser resfriado para temperaturas inferiores a $15^{\circ} \mathrm{C}$.

\section{Conclusões}

A suplementação com óleo de salmão na ração melhorou as características espermáticas no sêmen suíno descongelado em comparação ao uso de óleo de soja. O nível de vitamina E de $450 \mathrm{mg} / \mathrm{kg}$ de ração aumentou a porcentagem de espermatozoides vivos e reativos ao teste hiposmótico.

\section{Referências}

ALMLID, T.; STAVNE, S.E.; JOHNSON, A.L. Fertility evaluation of the straw freezing technique for boar semen under practical artificial insemination conditions. Zuchthygiene, v.22, p.193-202, 1987.

BIANCHI, I.; CORRÊA, M.N.; LUCIA JUNIOR, T. et al. Efeito de diferentes crioprotetores no descongelamento de sêmen suíno. In: CONGRESSO BRASILEIRO DE VETERINÁRIOS ESPECIALISTAS EM SUÍNOS, 12., 2005, Fortaleza. Anais... Fortaleza: Associação Brasileira dos Veterinários Especialistas em Suínos, 2005a. p.271.

BIANCHI, I.; CORRÊA, M.N.; PIASSI, L.M. et al. Efeito de diferentes métodos de congelamento sobre a motilidade de sêmen suíno. In: CONGRESSO BRASILEIRO DE VETERINÁRIOS ESPECIALISTAS EM SUÍNOS, 12., 2005, Fortaleza. Anais... Fortaleza: Associação Brasileira dos Veterinários Especialistas em Suínos, 2005b. p.273.

BUHR, M.M.; CURTIS, E.F.; KAKUDA, N.S. Composition and behavior of head membrane lipids of fresh and cryopreserved boar sperm. Cryobiology, v.31, p.224-238, 1994.

CEROLINI, S.; MALDJIAN, A.; PIZZI, F. et al. Changes in sperm quality and lipid composition during cryopresrvation of boar semen. Reproduction, v.121, p.395-401, 2001.

COLÉGIO BRASILEIRO DE REPRODUÇÃO ANIMAL - CBRA. Manual para exame andrológico e avaliação de sêmen animal. 2.ed. Belo Horizonte: 1998. 49p.

DE LEEUW, F.E.; CHEN, H.; COLENBRANDER, B. et al. Coldinduced ultrastructural changes in bull and boar sperm plasma membranes. Cryobiology, v.27, p.171-183, 1990.

ERICKSON, M.C. Chemistry and function of phospholipids. In: AKOH, C.C.; MIN, D.B. (Eds.) Food lipids, chemistry, nutrition and Biochemistry. New York: Marcel Dekker, 1998. p.41.

FERREIRA NETO, J.M.; VIANA, E.S.; MAGALHÃES, L.M. Patologia clínica veterinária. Belo Horizonte: Rabelo Brasil, 1977. 279p.

FÜRST, R.; CARVALHO, G.R.; FÜRST, M.C.O. et al. Efeito do resfriamento do semen equino sobre sua congelabilidade. Arquivo Brasileiro de Medicina Veterinária e Zootecnia, v.57, n.5, p.599-607, 2005.

JEYENDRAN, R.S.; VAN DER VEN, H.H.; PEREZ-PALAEZ, M. et al. Development of an assay to assess the functional integrity of the human sperm membrane and its relationship to other semen characteristics. Journal Reproduction and Fertility, v.70, p.219-225, 1984.

KING, G.J.; MACPHERSON, J.W. A comparison of two methods for boar semen collection. Journal of Animal Science, v.36, n.4, p.563-565, 1973.

KUMI-DIAKA, J. Subjecting canine semen to the hyposmotic test. Theriogenology, v.39, p.1279-1289, 1993.

MALDJIAN, A.; PIZZI, F.; GLIOZZI, T. et al. Changes in sperm quality and lipid composition during cryopreservation of boar semen. Theriogenology, v.63, p.411-421, 2005.

MARTIN, J.C.; KLUG, E.; GUNZEL, A.R. Centrifugation of stallion semen and its storage in large volume straws. Journal Reproduction and Fertility, v.27, p.47-51, 1979.

MAXWELL, W.M.C.; JOHNSON, L.A. Membrane status of boar spermatozoa after cooling or cryopreservation. Theriogenology, v.48, p.209-219, 1997.

MELO, M.I.V.; HENRY, M. Teste hiposmótico na avaliação do sêmen eqüino. Arquivo Brasileiro de Medicina Veterinária e Zootecnia, v.51, n.1, p.71-78, 1999. 
MURGAS, L.D.S.; SELLÉS, E.; GADEA, J. et al. Crioconservación espermática en la especie porcina: Estudio de dos sistemas de congelación con semen heterospérmico. In: CONGRESSO DA ABRAVES, 10., 2001, Porto Alegre. Anais... Porto Alegre: Associação Brasileira de Veterinários Especialistas em Suínos, 2001. (CD-ROM).

NATIONAL RESEACH COUNCIL - NRC. Nutrient requeriments of swine. 10.ed. Washington, D.C.: National Academy Press, 1998. 189 p.

NISSEN, H.P.; KREYSEL, H.W. Polyunsaturated fatty acids in relation to sperm motility. Andrology, v.15, p.264-269, 1983.

NIKI, E.; NOGUCHI, N.; GOTOH, N. Dynamics of lipid peroxidation and its inhibition by antioxidants. Biochemical Society Transactions, v.21, p.313-317, 1993.

OHATA, P.M.; BERNARDI, M.L.; REIS, G.R. et al. Congelabilidade do sêmen suíno de acordo com o período de equilíbrio précongelamento e da sensibilidade ao resfriamento. Archives of Veterinary Science, v.10, n.1, p.69-74, 2005.

OHATA, P.M.; WENTZ, I.; BERNARDI, M.L. et al. Influência do período de equilíbrio pré-congelamento e plasma seminal na congelabilidade do sêmen suíno. In: CONGRESSO DA ABRAVES, 10., 2001, Porto Alegre. Anais... Porto Alegre: Associação Brasileira de Veterinários Especialistas em Suínos, 2001. (CD-ROM).

PAQUIGNON, M.; BUSSIERE, J.; BARITEAU, F. et al. Résultats pratiques d'utilisation de semence congelee de verrat. Journées Recherche de la Porcine en France, v.9, p.19-21, 1977.

PAQUIGNON, M.; MERGOUNIS, D.; COUROT, M. et al. Technologie de la congélation de la semence de verrat: étude vitro. Journées de la Recherche Porcine en France, v.6, p. 71-76, 1974

PARKS, J.E.; LYNCH, D.V. Lipid composition and thermotropic phase behaviour of boar, bull, stallion and rooster sperm membranes. Cryobiology, v.29, p.255-266, 1992.

PAULENZ, H.; TAUGBOL, O.; KOMMISRUD, E. et al. Effect of dietary supplementation with cod liver oil on cold shock and freezability of boar semen. Reproduction in Domestic Animals, v.34, p.431-435, 1999.

PENNY, P.C.; NOBLE, R.C.; MALDJIAN, A. et al. Potential role of lipids for the enhancement of boar fertility and fecundity. Pig News Information, v.25, p.119-126, 2000.
PEREZ-LLANO, B.; LORENZO, J.L.; YENNES, P. et al. A short hypoosmotic swelling test for the prediction of boar sperm fertility. Theriogenology, v.56, p.387-398, 2001.

POUlos, A.; DARIN-BENNETT, A.; WhITE, I.G. The phospholipid-bound fatty acids and aldehydes of mammalian spermatozoa. Comparative Biochemistry Physiology, v.46, 541-549, 1973.

PURSEL V.G.; JOHSON L.A.; SCHULMAN L.L. Effect of diluition, seminal plasma and incubation period on cold shock susceptibility of boar spermatozoa Journal Animal Science, v.37, p.528-531, 1973.

PURSEL, V.G.; JOHNSON, L.A.; RAMPACEK, G.B. Acrosome morphology of boar spermatozoa incubated before cold shock. Journal Animal Science, v.34, p.278-283, 1972.

REESE, D.E. Omega-3 fatty acids and swine reproduction: a review. Nebraska Swine Reports, Animal Science Department University of Nebraska, 2003. p.30-33.

STEPONKUS, P.L.; DOWGERT, M.F.; GORDON-KAMM, W.J. Destabilization of the plasma membrane of isolated plant protoplasts during freeze-thaw cycle: the influence of cold acclimation. Cryobiology, v.20, p.448-465, 1983.

TONIOLLI, R.; BARROS, D.Q.; JATAHY, P.C. et al. Fertilidade de porcas inseminadas: análise de diferentes parâmetros. Revista Brasileira de Reprodução Animal, v.25, p.444-447, 2001.

UNIVERSIDADE FEDERAL DE VIÇOSA - UFV. Sistema para Análise Estatística e Genéticas - SAEG. Versão 8.0. Viçosa, MG, 2000. 142p.

VAZQUEZ, J.M.; MARTINEZ, E.A.; GARCIA-ARTIGA, C. et al. Hypoosmotic swelling of boar spermatozoa compared to other methods for analysing the sperm membrane. Theriogenology, v.47, p.913-922, 1997.

WATSON, P.F.; NOILES, E.E.; CURRY, M.R. et al. Response of spermatozoa to hyposmotic stress reflects cryopreservation success. In: INTERNATIONAL CONGRESS ON ANIMAL REPRODUCTION, 12., 1992, The Netherlands. Proceedings... The Netherlands: Society of Animal Reproduction, 1992. p. 1502 .

WESTENDORF, P.; RITCHER, L; TREU, H. Zur Tiefgefrierung von Ebersperma. Labor-und Besamungsergebnisse mit dem $\mathrm{Hu}$ "1senberger Paillettenverfahren. DtschTiera"rztl Wschr, v.82, p.261-267, 1975. 